\title{
Study on the Differences of Business Etiquette Between China and America From the Perspective of Cultural Dimensions
}

\author{
ZHAO Hong-xin, YU Gao-feng \\ University of Shanghai for Science and Technology, Shanghai, China
}

\begin{abstract}
Under different cultural background, the business etiquette is also different. Based on Hofstede's cultural dimensions theory, this paper analyzes the differences between China and America on business etiquette from the four aspects, including power distance, uncertainty avoidance, collectivism and individualism, and masculinity and femininity. According to the research, we can have a more specific and deeper understanding of these two countries' business etiquette. The paper will give some advice to people who want to do intercultural communication later and reach the anticipated goal.
\end{abstract}

Keywords: cultural dimensions, business etiquette, difference between China and America

\section{Introduction}

With the rapid progress of economic globalization, the national business communication is increasingly frequent and decent business etiquette also turns into intangible assets in business contacts. But it is worth noting that different countries vary widely in communication etiquette in business activity. China and America are the representatives of developing countries and developed countries as well as the representatives of Eastern and Western cultures, so it is meaningful to research business etiquette's differences between the two countries. As we all know, scholars in the field should not just study on the surface, but explore the deep-level culture. Unfortunately, most researches in the past only broadly studied the Sino-U.S. business etiquette; few articles related to Hofstede's cultural dimensions were reported.

\section{Hofstede's Cultural Dimension Theory}

Geert Hofstede (1991) is a famous Dutch psychologist. From 1967 to 1973, he made two studies in the IBM (International Business Machines) Company and surveyed about 116 thousand employees, which was the most large-scale study on employee's cultural values at that time. After this investigation, he considered that instead of an individual characteristic, culture is a mutual psychological process shared by people with the same education and life experience, which varies from different groups, regions, or countries (Hofstede, 1991). Finally, he put forward four important cultural dimension theories: power distance, uncertainty avoidance, individualism and collectivism, and masculinity and femininity. It is obvious that Hofstede's viewpoint has a great influence on

ZHAO Hong-xin, graduate student, Master candidate, College of Foreign Languages, University of Shanghai for Science and Technology, Shanghai.

YU Gao-feng, associate professor, M.A., College of Foreign Languages, University of Shanghai for Science and Technology, Shanghai. 
cross-cultural field and the whole process selected the multinational company personnel as the investigation object, so this theory has a coincident point with the study of cross-cultural business etiquette's differences. Therefore, this study on the differences of business etiquette between China and America from the perspective of cultural dimensions will contribute a lot to the successful cross-cultural communication.

\section{Differences of Business Etiquette Between China and America From the Perspective of Cultural Dimensions}

\section{Power Distance in Business Etiquette}

Power distance refers to social members' adaptation degree on the phenomenon of unfair power distribution. Generally speaking, hierarchic factors usually exist in countries with higher power index, where several differences can be amplified, including age, gender, and generational and social status. In contrast, countries with a lower distance index are different. Hofstede's research shows: Of all the investigated countries, the average power distance index is 55 among them; the index of China is 80, while the index of America is 40 . Therefore, from the perspective of power distance, China is a typical country with higher power distance, while America is a typical country with lower power distance.

Traditional Chinese culture is influenced by Confucianism and the deep connotation of "Etiquette" is "different". Some Chinese idioms have shown this phenomenon, for instance, "Officials should be subject to their monarch", "Son should be subject to his father," and "Wife should be subject to her husband". Confucianism believes that only each class keeps its etiquette, the social order could be stabilized. So in China's business situation, no matter how close their personal relations are, it is common for the inferior to use the names of occupations or positions as formal titles, such as Manager Wang, Supervisor Li, and Consultant Zhang. In this way, on the one hand, the subordinate can show his respect for the superior; on the other hand, the superior can gain respect from that humble behavior. Compared with China, America is a country where the "freedom and democracy" value is deeply rooted in people's mind. In America's business activities, it seems embarrassed or even strange to call the formal titles, if they share a good friendship with each other. This is especially common in business letters, for example, if inferior Peter and superior Tony are good friends, when Peter wants to email Tom to discuss some business affairs, it is proper for him to use "Dear Tony" as the message beginning. In China, it is a tradition to serve a feast for their guests on some special occasions, such as wedding, funeral, and marriage. At that time, there were some strict rules for a guest to choose a right seat, which also applies to business banquets: The seat, which locates in the middle and faces the door directly, is the seat of honor (Cardon, 2005). There is no doubt that these positions must be arranged strictly according to guests' degree of being admired, that is to say, people who belong to the old generation and high-status group have more opportunities to get such special seats, but similar rules do not exist in American's business banquet.

\section{Uncertainty Avoidance in Business Etiquette}

Uncertainty avoidance means the tolerance for future uncertainty and the acceptance for ambiguity that derives from people in specific cultural background. For example, people in high uncertainty avoidance try hard to avoid ambiguous and uncertain situation. They fear failure, refuse to change, but like routine. However, people in low uncertainty avoidance culture, on the contrary, tend to be more free and flexible. As for the uncertainty 
avoidance index, America is 30, while China is 46 . According to this dimension standard, America is a country with lower uncertainty avoidance.

Chinese employees always follow the inherent management rules and regulations in company, because they feel headache about system reform and never want to get the risk of potential salary cut and unemployment. Similarly, the company's managements also hold this view, which causes a quite common phenomenon in private companies: Even if employees have some advice for company's internal operations, they still dare not offer proposals easily. Because in traditional Chinese society, proposals offered for leaders (from ordinary staff) are not only confined to proposal itself, but also a lot of personal complaints about the leader. What is more, the inferior will take a risk of getting into trouble with the superior and suffering himself, if his superior does not agree with his proposal. Thus, in this kind of culture, the inferior will follow the intangible business etiquette above and try his best to avoid the occurrence of such uncertainty. But in America, employees can openly point out the problems existing in the company at the meeting. They are keen on innovation and do not like to be bonded by invisible rules, such as, the authority of experts or the position of superiors. Staff from all departments can discuss together and spark intelligence shines at the round table. At the same time, American companies encourage innovation and reform through promotion and pay raise. The "incredible business etiquette" in China is "unbelievable" for American businessmen due to cultural differences.

\section{Collectivism and Individualism in Business Etiquette}

Individualism culture emphasizes individual achievements and people attach great importance to the self-concept in this kind of cultural background, for instance, self-esteem, self identity, and self expression. That is to say, under individualism culture background, people believe that personal goal exceeds collective goal and individual is the most important factor in social location, which leads them to encourage competition. But collectivism culture works against individualism culture and people there do not attach great importance to self-concept, but follow strict social rules and put collective needs first. Therefore, people living in collectivism culture care others' opinions; saving face should be their first priority. Hofstede's research shows that individualism index in China is 20, ranking 56th-61st, while the index of individualism in America is 91, ranking first in the world.

The thought of Great Unification is an altruism-driven culture, which is also an essential part of Chinese ancient culture and ideology. It is common to see that no matter what the speaker wants to talk, the subjective must be some united words, like "we", for example, if a quick-minded employee is the major force of landing a big contract successfully, he would stress out that he is just a member of the whole collective and he would have achieved nothing without the endeavor of his far-sighted leaders and enthusiastic colleagues, in a word, he would attribute the whole success to the entire group which he belongs to. In addition, when it comes to decisions on major events, most employees usually follow the principle that "the minority is subordinate to the majority" in case of losing face; otherwise, he could be regarded as "a heterogeneous man" with no manners or business etiquette if he is stubborn and disputes with others for a long time. Likewise, they also need to consider other people's feelings and leave others room consciously when they express their opinions, even if they have personal disputes with someone, which also show their wise, implicit, and humble memes in business activities. But the American people possess the concept of individualism and they advocate "self-interest". Here 
are several examples: American staff usually give priority to "I" as the subject and they are always straightforward when expressing themselves and do not mind losing face at all. Moreover, they are keen on expressing personal views, paying great attention to the role of individuals in a team and they still believe "opportunities is in the hands of a few people", even if their ideas are against with the majority. When an American and a Chinese met at the first time, the American would feel strange if the Chinese lavished too much praise on the American's father, who was a pretty competent CEO in the company. Generally speaking, though they share kinship and work place, they are still independent individuals, therefore the conversation containing too much about others' glory may reflect the ignorance towards the American himself (Adair, 2004). Such conversation could not reach the greeting goal as expected, for this reason, people in business occasions should pay attention to such situation mentioned above.

\section{Masculinity and Femininity in Business Etiquette}

Masculinity or femininity dimension refers to the prevalence of masculine or feminine characteristic in specific cultural background. In masculine society, people attach importance to material success and different social orientations are expected for different genders: The male hold the dominant position and they represent great ambition, extraordinary courage, outstanding achievement, decisive behavior, and the inexhaustible competitiveness, while the female play the role of parenting, humility, and gentleness; but in society dominated by femininity dimension, both male and female concern much about the quality of life, gender equality, and interpersonal relations. Hofstede's research shows that the masculinity index in China is 66, ranking 11th-13th, while the masculinity index in America is 62, ranking 19th.

Both America and China are countries with masculinity, but when it comes to gender equality, America is a model in the world and few gender differences occur on business occasions there, because most Americans are affected by "chivalry"- advocating "lady first". Compared with America, gender stereotype still exists in modern China: Once a woman is married, she will give up her career and play the role of a housewife, heart and soul, while the man will continue his work to pursue higher salary or position. However, on the personal relation level, America is more inclined to masculinity dimension while China is more apt to femininity dimension. In China, the space distance between two employees reflects their potential intimacy level. For example, if two employees gained the same status in the company, the closer their relationship is, the shorter their body distance is and some colleagues even can talk personal privacy to bond closer to each other. In addition, Chinese people always attach importance to relations with partners and the maintenance of the regular customer by being enthusiastic as much as possible, in order to expand their business networks or avoid drawing water into others' mill. But in America, the relationship between business people is relatively apathetic; they would put efficiency in the first place and get the conversation to the point rather than show kindness to others by greeting, which coincides with their straightforward style of doing things (Adler, 1989). Besides, personal privacy is extremely important in America and it is an illegal behavior to ask applicants for their ID card number, birthday, age, or marital status.

\section{Conclusion}

Business etiquette varies with different cultural background and researches on business communication difference can not only affect the business transaction of the two countries, but also influence the development of 
world business communication. Based on the Hofstede's theory of cultural dimensions, this thesis analyzes some business phenomena in China and America respectively and concludes that business etiquette in China features high power distance, high uncertainty avoidance and collectivism, while business etiquette in America is characterized by low power distance, low uncertainty avoidance and individualism. As for the masculinity and femininity dimension of business etiquette, consistencies exist in the two big powers in the world and in the process of writing this part; the thesis compared Chinese and American business etiquette from gender equality and interpersonal relationship, in order to help people treat cultural differences in a more diverse way. Moreover, this thesis is expected to enrich people's knowledge on business etiquette differences between China and America, so as to avoid further business conflict between the two countries and achieve business goal more efficiently.

\section{References}

Hofstede, G. (1991). Cultures and organizations: Software of mind. New York: McGowan-Hill.

Cardon, P. W. (2005). Face: Western and eastern perspectives (172-184). Reston, VA: National Business Education Association. Adair, W. (2004). Culture and negotiation strategy. Negotiation Journal, 1, 87-100.

Adler, N. J. (1989). Cross-cultural interaction: The international comparison fallacy. Journal of International Business Studies, 20(3), 515-537. 